\title{
Ler de novo ou ler o novo? Práticas de leitura de crianças na biblioteca pública
}

Rafaela Vilela

Universidade Federal do Rio de Janeiro 2. Professora do Instituto Superior de Educação Pró-saber (Rio de Janeiro, RJ, Brasil)
Resumo: Este trabalho discute a leitura intensiva como uma prática de leitura recorrente na infância. Por que as crianças desejam tão frequentemente ler histórias já conhecidas? Qual o significado e a importância de ler de novo? Tratase de resultados de uma pesquisa de mestrado realizada em uma biblioteca pública com crianças entre 4 e 10 anos. Como estratégias metodológicas foram realizadas observações participantes, registros fotográficos, entrevistas semiestruturadas e conversas informais com as crianças frequentadoras do espaço. Os estudos de Bakhtin (1995, 2011), Benjamin (1994) e Vygotsky (1993) sustentam as concepções de linguagem e de sujeito, bem como as questões teórico-metodológicas de pesquisa. Para as discussões sobre leitura e infância buscou-se interlocução com os escritos de Chartier (1994, 2009), Corsino (2009, 2010), Larrosa (2002), Reyes (2012) e Yunes $(1995,2003)$.

Palavras-chave: Linguagem. Leitura literária. Crianças. Biblioteca pública. 
[...] uma leitura tem sua gênese nos olhos, na memória, nos desejos do leitor, que mobiliza sua vida para emprestá-la ao texto, e, ao mesmo tempo, aproveitar para que ele a redimensione (YUNES, 2003, p.13).

Este texto entrelaça discussões sobre leitura, infância e literatura a partir de resultados de uma dissertação de mestrado que teve como objetivo principal conhecer, analisar e compreender as práticas de leitura de crianças em uma biblioteca pública. A pesquisa empírica foi realizada entre os meses de janeiro e julho de 2013 em uma biblioteca estadual, localizada em uma comunidade da zona sul da cidade do Rio de Janeiro, com crianças entre 4 e 13 anos.

Com cinco andares e totalizando uma área de 1.600 metros quadrados, a biblioteca pesquisada exibe um projeto arquitetônico diferenciado. Possui ambientes amplos, modernos, bonitos e uma proposta que oferece a leitura em diversos suportes, concebendo espaços diferentes para leituras diferentes. Para isso, disponibiliza uma biblioteca com mais de 12 mil títulos, midiateca, ludoteca - a biblioteca infantil, cineteatro, uma sala multiuso para cursos, setor de internet comunitária, cozinha-escola e café literário. Em campo, percebemos que as crianças escolhiam e circulavam, em sua maioria, por três ambientes: o espaço dos computadores, a midiateca e a ludoteca. Mas como observar as crianças em todos esses espaços? 0 barulho presente no espaço dos livros, em contraponto com o silêncio dos ambientes que tinham computadores e televisões, fez com que a ludoteca fosse eleita como foco para as observações participantes.

Neste texto escolhemos discutir uma prática de leitura recorrente no encontro entre crianças e livros: a leitura intensiva. Por que as crianças desejam tão frequentemente ler histórias já conhecidas? Qual o significado e a importância de ler de novo? Lugar onde podem escolher o que ler e como ler, a ludoteca foi cenário para os fragmentos aqui reunidos. Eventos que apostam no discurso como uma forma de dialogar com o nosso tempo e a nossa cultura. Uma pequena coleção que, além de dizer das escolhas e dos modos de ler das crianças, reafirma a leitura como um ato que envolve compreensões éticas e estéticas da língua e da vida. Fragmentos que afirmam a escolha das crianças em estar em um ambiente onde a literatura se faz presente. Uma literatura que atravessa, afeta, altera e reúne. Uma leitura que parece ser compreendida pelas crianças frequentadoras da biblioteca não como dever, mas como opção para estar junto. 
Os estudos de Bakhtin (1995, 2011), Benjamin (1994) e Vygotsky (1993) sustentam as concepções de linguagem e de sujeito, bem como as questões teórico-metodológicas de pesquisa. Para as discussões sobre leitura e infância buscou-se interlocução com os escritos de Chartier (1994, 2009), Corsino (2009, 2010), Larrosa (2002), Reyes (2012) e Yunes (1995, 2003). 0 caminho teórico-metodológico escolhido para a construção da pesquisa considera que os sujeitos são constituídos na e pela linguagem, na relação com a cultura e com o outro. Uma linguagem compreendida enquanto enunciação, em que as respostas dos sujeitos são réplicas situadas e marcadas por suas formas de ser e estar no mundo (BAKHTIN, 1995). Compreensões que tecem e são tecidas em teias de significados, simultaneamente individuais e coletivas.

A partir dessa perspectiva, que envolve a escuta sobre o que as crianças têm a dizer, reconhecendo-as como interlocutoras que possam falar por si e sobre si, elegemos como procedimentos metodológicos de pesquisa observações participantes, registros fotográficos, entrevistas semiestruturadas e conversas informais com as crianças frequentadoras do espaço.

As reflexões sobre leitura presentes neste texto foram compostas a partir da análise de dois eventos observados no espaço da ludoteca e registrados em caderno de campo. Partimos da ideia de evento como um momento irrepetível de interlocução, possível de ser capturado e registrado pelo pesquisador por meio da observação participante. Uma observação que, de acordo com Freitas (2003, p. 33), se constitui em um “encontro de muitas vozes: ao se observar um evento, depara-se com diferentes discursos verbais, gestuais e expressivos. São discursos que refletem e refratam a realidade da qual fazem parte construindo uma verdadeira tessitura da vida social”.

Para Bakhtin (1995, 2011), a palavra é o elo entre o eu e o outro. Na enunciação de um discurso, as palavras se revestem de significados e possibilitam maneiras singulares de estar e compreender o mundo. Geraldi (1997) contribui para o entendimento dessas considerações afirmando que "os sujeitos se constituem como tais à medida que interagem com os outros. [...] Neste sentido, o sujeito é social. [...] Também não há sujeito dado, pronto, que entra na interação, mas um sujeito se completando e se constituindo nas suas falas” (p. 6).

A observação participante é marcada pela alteridade. Apesar de o pesquisador constituir-se parte do evento observado na medida em que participa dele, é capaz de, pelo movimento exotópico, distanciar-se para descrever e discutir os textos e os contextos da observação realizada. Para Bakhtin (2011), ninguém consegue se ver por inteiro. Somente o outro, através de seu olhar excedente e exotópico, pode ampliar o que o sujeito vê de si mesmo. Isso significa que para compreender o outro, o pesquisador, ao mesmo tempo que precisa ir ao 
lugar desse outro, deve retornar ao seu lugar. É por meio dessa experiência de alteridade que ele poderá dialogar com os discursos dos sujeitos da pesquisa. Nesse sentido, o evento apresenta, além do olhar do pesquisador, as diversas vozes dos sujeitos participantes da pesquisa, considerando a perspectiva discursiva, dialógica e polifônica da observação e do registro.

Com o objetivo de refletir sobre a leitura intensiva como prática de leitura recorrente na infância, organizamos o texto em três partes: a primeira apresenta considerações sobre a leitura e a literatura; em seguida tece a análise de dois eventos de leitura de crianças na ludoteca; e por fim, conclui com reflexões que afirmam a leitura intensiva como um movimento importante de leitura das crianças.

\section{DIÁlogos COM A LEITURA}

A palavra leitura é derivada do termo latim legere e, segundo o dicionário Houaiss (2009), significa recolher, escolher, captar com os olhos. Escolhas e apreensões de mundo que nos constituem enquanto sujeitos, pois ler é sempre um ato de apropriação. São os encontros com a cultura escrita, seus usos e as formas de compreensão dos materiais impressos que constituem a leitura enquanto prática criadora, produtora de sentidos. Mas o entendimento de que ler é mais do que decodificar letras e formar palavras está conectado intimamente a uma concepção que compreende a linguagem para além de um sistema ou instrumento de comunicação.

O filósofo Mikhail Bakhtin (1995) aponta que o sujeito se constitui na linguagem enquanto um ser histórico e social, inserido numa dada cultura. “É na tensão do encontro/desencontro do eu e do tu que ambos se constituem. E nessa atividade, constrói-se a linguagem enquanto mediação sígnica necessária. Por isso a linguagem é trabalho e produto do trabalho” (GERALDI, 2003, p. 19). Assim, pensar a relação com outro significa pensar em uma relação dialógica.

Em consonância com essa concepção, Franchi (2011, p. 55) considera que “[...] a linguagem é construção de pensamento; e antes de ser veículo de sentimentos, ideias, emoções, aspirações, a linguagem é um processo criador em que organizamos e informamos as nossas experiências”. Essa concepção de linguagem, compreendida enquanto uma atividade constitutiva, relacionase intrinsecamente ao seu caráter histórico. É nesse sentido que Bakhtin 
(1995) afirma que não há a primeira nem a última palavra, e sim um fluxo ininterrupto de comunicação verbal. Portanto, não se trata de um recomeçar, nem de um repetir, mas de uma construção pautada em um processo social e cultural. Assim, a linguagem precisa ser considerada não como um resultado, mas como um processo dialógico.

Para Bakhtin (1995, 2011), a palavra é o elo entre o eu e o outro. Na enunciação de um discurso, as palavras se revestem de significados e possibilitam maneiras singulares de estar e compreender o mundo. Geraldi (1997) contribui para o entendimento dessas considerações afirmando que "os sujeitos se constituem como tais à medida que interagem com os outros. [...] Neste sentido, o sujeito é social. [...] Também não há sujeito dado, pronto, que entra na interação, mas um sujeito se completando e se constituindo nas suas falas" ( $p .6)$.

Construção aberta e criativa, a linguagem não é exterior ao sujeito, mas está em uma relação complexa de exterioridade-interioridade. Os estudos de Lev Vygotsky consideram uma estreita relação entre pensamento e linguagem. Para o autor, "o pensamento não é simplesmente expresso em palavras: mas é por meio delas que passa a existir" (VYGOTSKY, 1993, p. 108). Assim, a apresentação da realidade se dá na e pela linguagem, implicando diretamente a construção da consciência do sujeito e sua relação com a realidade. Desse modo, tanto o pensamento alimenta a linguagem quanto a linguagem sustenta o pensamento, sendo ambos indissociáveis.

Para Walter Benjamin, de acordo com Corsino (2009, p. 220), a linguagem é a “'casa' das ideias, é na e pela palavra que as ideias podem ser formuladas e comunicáveis a nós mesmos e ao outro. A realidade nos é apresentada pela linguagem, ela existe e se expressa na língua, nos possibilitando também conhecê-la e expressá-la”. Benjamim (1994) defende uma teoria mimética da linguagem, considerando o gesto como o primeiro meio de criação linguística e reforçando a ideia de uma linguagem expressiva, vista não apenas como meio de comunicação, mas como uma revelação da nossa essência.

Para Chartier (1994, p. 16), a “leitura não é somente uma operação abstrata de intelecção; ela é engajamento do corpo, inscrição num espaço, relação consigo e com os outros". Partilhando dessa ideia, Yunes (1995, p. 185) aponta que "o ato de ler é um ato da sensibilidade e da inteligência, de compreensão e de comunhão com o mundo". Leitura que amplia a condição humana, especialmente no e pelo encontro com a linguagem arte, pois "a literatura se abre a múltiplas interpretações e permite o encontro de si mesmo e do outro, instaurando a linguagem na sua dimensão expressiva" (PERROTTI, 2004, p. 24). 
Para Andruetto (2012, p. 54), “vamos à ficção para tentar compreender, para conhecer algo mais acerca de nossas contradições, nossas misérias e nossas grandezas, ou seja, acerca do mais profundamente humano". A literatura, ao "acolher a experiência humana e decantá-la nessa linguagem-outra que é a linguagem dos símbolos" (REYES, 2012, p. 82, grifos da autora), permite um diálogo interior e um modo de processar a realidade, possibilitando criar outros/novos discursos. Discursos que possam nos comover, nos levar além.

\section{LER DE NOVO OU LER O NOVO?}

Do volumen ao códex, do manuscrito ao impresso, a múltipla circulação do escrito, iniciada com a imprensa e difundida pelas mídias eletrônicas, tem transformado as práticas de leitura ao longo dos séculos. Chartier (1994, 2009), ao apresentar uma história da leitura e discutir as diferentes práticas construídas entre leitor e texto ao longo dos tempos, contribui para refletirmos sobre o conceito de leitura intensiva.

$\mathrm{Na}$ antiguidade, a leitura intensiva esteve relacionada, de forma direta, à escassez de registros escritos. Os poucos textos circulantes e o alto índice de analfabetismo resultavam em uma leitura fundamentada na memorização e na recitação. Essa prática acontecia, geralmente, em voz alta e associava-se fortemente ao objetivo da declamação e da escuta, permanecendo enquanto "cimento fundamental de diversas formas de sociabilidade familiar, erudita, mundana ou pública" (CHARTIER, 1994, p. 98). Uma prática que confirmava o leitor como aquele que declamava os textos mas, também, aquele que escutava a declamação - leitor narrador e leitor ouvinte, respectivamente.

Foi a ampliação e a popularização dos escritos, ainda na segunda metade do século XVIII, que contribuiu de forma significativa para que o leitor extensivo entrasse em cena, marcando uma revolução nos modos de ler. Para Chartier (1994, p. 100), “o crescimento da produção do livro, a multiplicação e a transformação dos jornais, o sucesso dos pequenos formatos, a redução do preço do livro, graças às cópias, a proliferação das sociedades de leitura como as bibliotecas de empréstimo" foram os responsáveis pela disseminação da cultura escrita.

Embora ainda se faça presente em instituições como a igreja e a escola, a leitura intensiva, realizada em voz alta, mostra-se cada vez menos presente na sociedade contemporânea, visto que ler com os olhos e em silêncio oferece a oportunidade de "se ler mais rápido, logo, de se lerem mais textos, bem como de se lerem textos mais complexos" (CHARTIER, 1994, p. 98). Observamos, 
porém, que junto às crianças pequenas ela é uma prática recorrente. Por que as crianças desejam tão frequentemente ler histórias já conhecidas? Qual a importância de ler de novo? Os eventos a seguir dialogam com essas questões e apontam a repetição como um movimento importante de leitura das crianças.

“TOdO LIVRO É DE LER!”

Em “Todo livro é de ler!”, Tatiana, Vitor e Renata buscam repetir a experiência da leitura realizada pela mediadora Alessandra na ludoteca no fim de semana. Juntos, os três leem um livro de imagem e contribuem para a discussão de que o texto é mais que uma enunciação exclusivamente verbal.

"Todo livro é de ler!"

Chegando ao espaço da ludoteca, Tatiana se dirigiu a mim com um convite:

[...] a gente pode fazer uma roda de livro e de brincadeira igual a que a tia Alessandra fez no sábado? Foi muito legal!

Diante do meu interesse, ela foi correndo pegar o livro Telefone sem fio (BRENMAN; MORRICONI, 2010). Sentamos juntas. Vitor chegou perto e disse:

Eu também adorei esse livro. Posso ler?

Tu não sabe ler! - falou Renata.

Esse livro eu sei ler!

Vitor pegou o livro da mão de Tatiana e começou:

Era a história do palhaço que queria contar um segredo...

Ai!!! Esse livro não tem nada para ler! Nem tem letra! Você está inventando!

Não tem letra, mas tem desenho, olha?! Todo livro é de ler! Esse aqui é de ler pelo desenho, né não, tia? A gente lê contando o que está acontecendo.

Isso é inventar... não é ler!

Esse livro é diferente porque ele não tem texto, só imagem. Mas ele também conta uma história, não é mesmo? - perguntou a mediadora Alessandra.

Renata ficou inconformada. Pegou outro livro e sentou-se no pufe sozinha. Tatiana e Vitor começaram a leitura.

Era uma vez um palhaço que tinha uma coisa para contar que ninguém sabia. Era segredo, mas ele contou para o rei. 
Aí o rei falou para o cavaleiro. E o cavaleiro falou um segredo para o mergulhador, mas ele estava com uma coisa na cabeça.

É! Ele estava com um capacete de moto e não ouviu direito. E contou outra coisa maluca para o Pirata do Caribe [risos]. E o pirata falou para o papagaio.

Papagaio não fala! - Renata falou do pufe.

Esse fala! E o papagaio falou curupaco para o índio. E o índio falou tudo para o moço que tira foto.

É o turista, olha a camisa! E ele falou para a moça rica.

Para madame! - emendou Renata, que já estava mais perto dos dois.

E a madame cheia de joia e toda chique falou para a vovozinha, que depois falou para o Lobo [risos].

E o lobo falou para a Chapeuzinho Vermelho: "Eu vou te comer!”. A Chapeuzinho fugiu para o caçador. E o caçador contou um segredo para o cachorro, mas como cachorro não fala, ele deu um lambidão no bobo da corte. Ele ficou todo babado e fedorento.

Fim!

Tia Alessandra, empresta o tubo pra gente fazer telefone!

(Caderno de campo, 10 abr. 2013)

O evento "Todo livro é de ler!" se inicia com o convite de Tatiana que, desejante por repetir a leitura realizada pela mediadora no fim de semana, procura o livro Telefone sem fio (BRENMAN; MORRICONI, 2010) na estante. A "roda de livro e brincadeira", como definiu a menina, constituiu-se enquanto experiência e produziu rastros na memória, pois só desejamos repetir aquilo que, ao produzir afetos, nos afeta e instaura marcas (LARROSA, 2002).

A rapidez em encontrar o título aponta a intimidade de Tatiana com o espaço e o acervo da biblioteca. Apesar de me convidar para a leitura, é ao lado de Vitor e Renata que a narrativa do livro de imagem se constrói. Vitor começa a ler. Renata, que o conhece da escola, sabe da dificuldade do menino em relação à leitura de palavras. Mas, diante da enunciação “tu não sabe ler!", Vitor aponta novas possibilidades de leitura. Ler as ilustrações de um título já conhecido é certeza de sucesso: “Esse livro eu sei ler!”. O letramento literário, sua vivência como leitor ouvinte, lhe permite antecipar a obra e compreender que um livro sem letras também pode ser lido, afinal “todo livro é de ler!”. Mesmo com a entrada da mediadora, Renata precisa de tempo e espaço para refletir se é possível ler uma imagem e se a leitura pode ser um tipo de 
“invenção”. Vitor estava lendo ou inventando? O que significa ler? Enquanto a menina se afasta, Vitor e Tatiana começam o jogo de leitura (PEREIRA, 2007).

O livro é composto por ilustrações grandes, retratadas com cores intensas e traçado preciso. Como na brincadeira do telefone sem fio, o segredo cochichado no ouvido passa de página em página. Do palhaço para o rei, do rei para o cavaleiro, do cavaleiro para o mergulhador. Mas como o mergulhador poderia ouvir tal mistério com um capacete na cabeça? A imagem provoca e convoca as crianças a trazerem seus conhecimentos de mundo para dialogar com 0 livro. 0 pirata do Caribe ouve e passa para o papagaio, que conta para o índio, que fala para o moço que tira foto. Fotógrafo ou turista, é ele quem continua o jogo falando para a moça rica. Com joias e óculos escuros, é essa ilustração que captura Renata e a traz de volta para a roda. O segredo, então, passa para a avó, que conta para o lobo que, por sua vez, tenta comer Chapeuzinho Vermelho. A menina chama pelo caçador e este sussurra palavras para 0 cachorro, que termina o livro lambendo o personagem inicial, nomeado agora de bobo da corte pelas crianças. A brincadeira ainda continua quando Vitor, Tatiana e Renata transformam um rolo de papelão em telefone e se divertem enunciando segredos aos quatro ventos.

O evento exibe a leitura pelo viés da experiência e do jogo. Experiência que para Benjamin (1994) se entrelaça à capacidade de narrar e de estabelecer elos de coletividade. No encontro com o texto, o leitor é capaz de ampliar a capacidade de realizar novas leituras de si, do outro e do mundo.

A experiência, a possibilidade de que algo nos aconteça ou nos toque, [...] requer parar para pensar, parar para olhar, parar para escutar, [...] cultivar a atenção e a delicadeza, abrir os olhos e os ouvidos, falar sobre o que nos acontece, aprender a lentidão, escutar aos outros, cultivar a arte do encontro, calar muito, ter paciência e dar-se tempo e espaço (LARROSA,

Definitivamente, ler é "uma prática que se aprende, que se constrói, que se conquista, que demanda tempo" (BAJOUR, 2012, p. 45). São esses encontros que, ao entrelaçar o dizer e o ouvir, garantem tempo e espaço para a partilha, a negociação e a criação de novos sentidos, pois a experiência está justamente na possibilidade de transbordar memórias, de emergir e narrar aquilo que nos marca e afeta. As narrativas são um meio de não se perder a história, de congregar passado, presente e futuro e de nos conhecermos e reconhecermos na experiência alheia. A narrativa é assim compreendida como uma forma artesanal de comunicação, que necessita de tempo para acontecer. Narrar e ouvir histórias relaciona-se a uma atmosfera que não é cronológica, pois se constitui em uma temporalidade não mensurável baseada na intensidade e 
que encontra no tédio espaço para acontecer. Para ser apreendida, a narrativa necessita de um ouvinte entregue, pois "quanto mais o ouvinte se esquece de si, mais profundamente se grava nele o que é ouvido" (BENJAMIN, 1994, p. 205). Tatiana, Vitor e Renata estabelecem no espaço da biblioteca tempo para o encontro e elegem a leitura literária como elo de relações. Por meio de uma narrativa pautada na imagem, o livro congregou de forma singular e plural as experiências das crianças.

A palavra jogo, por sua vez, "recupera a ideia da leitura como algo que, sendo divertido, imaginativo e gracioso, é portanto da ordem da estética” (PEREIRA, 2007, p. 31). Assim, a principal característica da leitura enquanto jogo é a de envolver o sujeito inteiramente, com liberdade, transportando-o para tempos e espaços múltiplos, no trânsito entre o real e o imaginário. Pereira (2007) ressalta que a literatura, ao articular conhecimento e vida, adquire uma função essencial nos jogos de linguagem, posto que é capaz de provocar uma rede de saberes entre os sujeitos. Bakhtin (2011), ao propor uma relação viva com a palavra, destaca que a vida está sempre em movimento e, pela possibilidade de ser olhada a partir de diferentes ângulos, ela se renova constantemente apresentando novos/outros sentidos. Vida e língua se constituem nos acontecimentos. Assim, também a linguagem vive esse jogo de ser igual e diferente ao mesmo tempo.

O que significa ler? Yunes (1995, p. 188) aponta que ler é "interrogar as palavras, duvidar delas, ampliá-las. Deste contato, desta troca, nasce o prazer de conhecer, de imaginar, de inventar a vida”. “Todo livro é de ler?” É possível ler um livro que não possui letras? O evento revela que as crianças não se limitam a simplesmente descrever imagens, mas usam as ilustrações para construir uma narrativa com elas. O livro de imagem é constituído pela linguagem visual e é mais uma forma de apresentar o mundo e de evocar enunciados a partir de margens, formas, cores, composições. A leitura de imagens não é fácil nem simples, pois precisa de um olhar estético para ser compreendida e narrada. Assim, faz-se necessário aprender a ver, demorarse e perder-se nos traços imbricados pelo ilustrador-autor, entrar na sintaxe da imagem. É nesse labirinto que o leitor irá criar seu percurso e preencher os espaços da imagem/texto com sentidos próprios. Belmiro (2012) defende a necessidade de considerar uma relação entre ver e ler, "adicionando ao ver estatuto de ler alguma coisa e, ao ler, as condições de poder ver alguma coisa. $\mathrm{O}$ que os une é o dizer e isso solicita uma discursividade que recupera a 
presença dos interlocutores e seus atos de fala" (BELMIRO, 2012, p. 127, grifos da autora). A literatura, enquanto arte, necessita da entrada da imaginação e da sensibilidade do leitor para se constituir plena, pois o texto só se completa no ato da leitura.

\section{“Aí só TEM LIVRo DIFíCIL DE LER!”}

O desejo de ler de novo também aparece no evento "Aí só tem livro difícil de ler!”. Tatiana chega à ludoteca no momento em que eu e Renata estávamos compartilhando leituras, lendo juntas. Renata propõe que a amiga se junte a nós e que escolhamos novos livros. As meninas, com intimidade de sobra, circulam pelo espaço e buscam nas estantes os livros desejados. Uma busca que contribui para pensarmos sobre as escolhas das crianças e a sua relação com a leitura.

“Aî só tem livro difícil de ler!”

Tatá, vem aqui ler com a gente! Escolhe um livro que você gosta muito - convida Renata.

[...] Tatiana embarca no convite.

Dirigi-me para a prateleira que fica mais próxima aos computadores.

Tia, não escolhe livro daí não porque aí só tem livro difícil de ler.

É mesmo? Por quê?

Percebi que havia uma etiqueta que categorizava aquela estante como "livros com muito texto e poucas ilustrações”.

A gente gosta de escolher dessa estante aqui, porque esses daí não têm muito desenho e com desenho é mais legal.

Livros escolhidos, sentamos juntas nos pufes.

Tatiana abriu o livro Boladas e amigos (MACHADO, 1995) e começou a ler.

Esse eu sei ler muito bem porque tem na minha sala e eu já li muitas vezes - disse Tatiana

É, tia, ela sempre escolhe esse porque é fácil.

É fácil? Por quê?

Porque, olha aqui - disse Renata tirando o livro da mão da Tatiana -, o texto é pequeno. Tem pouquinha coisa.

Mas só porque o texto é pequeno ele é fácil?

Eu acho que é porque aí demora menos para ler, entendeu? 
Você concorda, Tatiana?

Eu sempre escolho livro que não tem muita coisa para ler porque senão eu fico cansada.

Viu, tia?

Mas eu escolhi esse porque eu gosto da história também.

Renata se encostou em mim e acompanhou toda a narrativa, depois elogiou:

Ela sabe ler direitinho, né? Nem demora.

O que é um livro difícil de ler? De acordo com o dicionário Houaiss (2009), difícil é tudo aquilo que exige esforço, que oferece obstáculos. É um trabalho laborioso e árduo. 0 que torna a leitura de um livro fácil ou difícil? Que critérios as crianças usam para categorizar os livros? O evento "Aí só tem livro difícil de ler!" possibilita olhar a leitura como um processo complexo que envolve aprendizados linguísticos específicos. Habilidades que, segundo Colomer (2007), envolvem rapidez, concentração e autocontrole. Tatiana e Renata compreendem isso. Sabem que existe uma performance envolvida na leitura em voz alta. Ler para o outro requer leitura proficiente, na qual seja possível "ler direitinho", sem demorar. Para isso, dentre os títulos expostos, as meninas buscam, entre os livros já conhecidos, os que trazem, em uma mesma medida, texto e ilustração, pois, como apontam, livro "com desenho é mais legal". Tatiana e Renata veem na ilustração uma forma de leitura. Leitura que também permite uma pausa e/ou um apoio para identificar as passagens da narrativa. Ilustração que quando estabelece “uma leitura própria, propositiva e criativa, em que forma e conteúdo, ética e estética ganhem a dimensão artística", é capaz de instituir um diálogo entre o verbal e o não verbal, tornando o texto polifônico (CORSINO, 2010, p. 192).

Esta relação entre texto e leitor é construída a cada vez que o sujeito abre um livro para ler. Há um aprendizado que se inicia desde o folhear de páginas até a compreensão e a interpretação do enredo. São práticas que permitem aos sujeitos apropriar-se da cultura escrita. As amigas, ao afirmarem que eu não encontraria um bom título na prateleira de "livros com muito texto e poucas ilustrações”, apontam que um texto longo, corrido, é mais trabalhoso para ler e, por isso, mais difícil. Ao anunciar que Tatiana "sempre escolhe esse [livro] porque é fácil”, Renata associa o tamanho do texto ao esforço de leitura, pois como "tem pouquinha coisa", “demora menos para ler". A amiga, apesar de concordar com a enunciação, justifica uma escolha pautada no gosto: "eu escolhi esse porque eu gosto da história também”. Gosta porque já leu muitas 
vezes ou já leu muitas vezes porque gosta? Será que o contato repetido com um livro, a leitura intensiva a que se refere Chartier (1994), forma também o gosto?

A experiência literária das meninas é o que permite esse diálogo. Livros fáceis, para elas, são os já lidos. Quando Tatiana anuncia "esse eu sei ler muito bem porque tem na minha sala [de aula] e eu já li muitas vezes", ela revela a possibilidade que o conhecido oferece de antecipar e prever os discursos e as palavras. Leitura intensiva que proporciona “ler, reler, debruçar-se sobre os mesmos textos, duvidar, escolher sentidos possíveis, resgatando, neste gesto, a etimologia da palavra leitura" (SILVA; MARTINS, 2010, p. 29). Uma leitura que, apesar de repetida, possibilita a criação de novos significados para a narradora e as ouvintes.

Nesse viés, o evento "Aí só tem livro difícil de ler!” propõe pensar a leitura intensiva a partir das estruturas cognitivas e das experiências socioculturais. Cognitivas, pois ler envolve um engenhoso processo que inclui, segundo Kleiman (1996), a percepção e a memória. Sociocultural, pois é possível perceber na escolha realizada pelas meninas experiências já construídas na relação com o livro e com a leitura.

De acordo com Kleiman (1996), ao ler, o sujeito primeiro realiza um movimento de percepção do material que, ao ser processado, faz com que os traços no papel ganhem significados. Uma vez que o traço é reconhecido como letra ou palavra, transforma-se em uma imagem acústica ou visual que precisa ser mantida na memória pelo leitor até que se torne uma unidade reconhecível capaz de ser proferida e fazer sentido dentro de seu contexto linguístico. Um processo, de fato, complexo. Talvez, por isso, as crianças que já dominam esse processo, mas que ainda não o fazem com proficiência, prefiram realizar a leitura intensiva, pois ler o conhecido contribui para evocar essa memória visual. Isso irá favorecer a fluência e permitirá ao leitor narrador atentar para o tom de voz e para as pausas previstas na pontuação, posto que há uma performance envolvida na leitura com e para o outro.

Podemos compreender, a partir desses indícios, que o leitor precisa dispor e articular os diversos conhecimentos que possui acerca da língua para chegar à compreensão do escrito. Compreensão que, apesar de considerar a decodificação das palavras, visto que "precisamos dessas ferramentas para fazer leituras livres e transgressoras" (REYES, 2012, p. 25-26), vai para além desta, pois compreender um texto significa preenchê-lo com sentidos próprios. 
Apesar de ser um processo complexo, entendemos, assim como Manguel (1997, p. 54), que “ler não é um processo automático de capturar um texto como um papel fotossensível captura a luz, mas um processo de construção desconcertante, labiríntico, comum e, contudo, pessoal”. Desse modo, os momentos de leitura intensiva mostram-se fundamentais para que os sujeitos possam, pelo contato com a linguagem literária, "entrar na cadeia significante, elaborar continuamente interpretações que dão sentido ao mundo, registrála com palavras, gestos, traços. Ler é significar e ao mesmo tempo tornar-se significante" (YUNES, 1995, p. 195).

A leitura literária oferece para o leitor a ampliação das estruturas cognitivas e das experiências socioculturais. Tatiana, ao escolher ler o conhecido, nos convida a pensar nos acervos oferecidos para as crianças nos mais diferentes espaços. Que títulos as crianças têm tido a oportunidade de ler sozinhas e com seus pares? Que livros têm sido escolhidos pelos adultos para a leitura mediada com e para as crianças? Quando se trata de leitura, é importante equilibrar ampliação e intensidade, pois ler de novo é quase tão importante quanto ler o novo. Assim, os livros dados a ler passam a compor o repertório das crianças, tornando-se os conhecidos. Muitas vezes tornam-se até os preferidos, posto que só gostamos daquilo que conhecemos.

As crianças desejam ler, individualmente ou em pequenos grupos, livros que os adultos já leram para elas. Dessa forma, do mesmo modo que é importante selecionar livros para as rodas de leitura, também é fundamental oferecer uma coleção de títulos literários de qualidade para os momentos de leitura livre. Muitas vezes os livros são separados entre os que os adultos usam para ler e os que as crianças podem mexer. É importante que os espaços de leitura disponibilizem livros que congreguem narrativa, ilustração e um projeto gráfico de qualidade. Livros bonitos, novos, que possam convidar o folhear das páginas e capturar a atenção do leitor.

Em uma cultura que estimula a leitura silenciosa, em que se lê principalmente com os olhos, valorizar a leitura em voz alta permite criar tempos e espaços para a escuta. A leitura socializada, além de contribuir para o desempenho leitor, congrega e precisa fazer parte "de nossa identidade cultural, nosso modo de ser e de agir coletivos” (PERROTTI, 2004, p. 11). 


\section{CONSIDERAÇÕES FINAIS}

O presente trabalho teve como objetivo discutir a leitura intensiva como uma prática de leitura recorrente entre as crianças no cotidiano de uma biblioteca pública. Para isso, assumimos uma concepção de linguagem como enunciação, discurso constitutivo do sujeito, no qual palavras e imagens compõem um mosaico de possibilidades de construção e produção de sentidos.

O desejo das crianças em ler o conhecido suscita algumas considerações importantes. O evento "Todo livro é de ler!" permite refletir sobre os significados da leitura intensiva. Ao buscarem repetir a leitura feita pela mediadora, as crianças nos convidam a pensar que o conhecido, ao ganhar novos sentidos, é capaz de tornar-se inédito. 0 movimento de ler um livro que não possui letras revela que as crianças não se limitam a simplesmente descrever imagens, mas usam as ilustrações para construir uma narrativa com elas. Uma leitura que não é fácil nem simples, pois envolve entrar numa sintaxe própria e perceber as diferentes camadas presentes no texto visual. 0 evento ainda permite compreender a leitura pelo viés da experiência, pois ao romper com o tempo imediato, o desejo de ler de novo aparece como uma forma de revisitar as sensações experimentadas - particular e coletivamente, pois só desejamos repetir aquilo que, de alguma forma, nos atravessa e afeta.

“Aí só tem livro difícil de ler!” discute a leitura a partir das estruturas cognitivas e das experiências socioculturais. 0 evento destaca o ato de ler como um processo complexo, que envolve aprendizados linguísticos específicos, em que ler para o outro requer uma performance, "ler direitinho". Para isso, dentre os títulos expostos, as crianças buscam os livros já conhecidos. Assim, é possível afirmar que os "livros fáceis", para elas, são os já lidos. Leitura intensiva que possibilita antecipar e prever os discursos, as palavras. Repetição que também considera que a formação do gosto do leitor passa pela leitura intensiva.

As crianças, ao abrir o mesmo livro, ao escolher ler uma mesma história, buscam algo novo no conhecido. Um movimento recorrente ora porque se identificam com os personagens e buscam elaborar medos e conflitos, ora para se apropriar da linguagem escrita e aprender a ler melhor, ora também para repetir uma experiência significativa. Nesse sentido, a pesquisa aponta a leitura intensiva como um importante movimento de negociação e a produção de novos sentidos. 


\section{Read again or read anew? Children's reading practices in a public library}

Abstract: This study discusses repeated reading as a recurring reading practice in childhood. Why do children so often wish to read stories already known to them? What is the meaning and the importance of reading again? We present the results of a master's research project conducted in a public library with children aged 4 to 10 years. Our methodological strategies consisted of participant observations, photographic records, semi-structured interviews and informal conversation with children who regularly used the library. The studies of Bakhtin (1995; 2011), Benjamin (1994) and Vygotsky (1993) were used to underpin the concepts of language and subject, as well as for approaching theoretical and methodological questions. For discussions about reading and childhood, we sought to dialogue with the writings of Chartier (1994; 2009), Corsino (2009; 2010), Larrosa (2002), Reyes (2012) and Yunes (1995; 2003).

Keywords: Language. Literary reading. Children. Public library. 


\section{REFERÊNCIAS}

ANDRUETTO, María Teresa. Por uma literatura sem adjetivos. São Paulo: Editora Pulo do Gato, 2012.

BAJOUR, Cecilia. Ouvir nas entrelinhas: o valor da escuta nas práticas de leitura. São Paulo: Editora Pulo do Gato, 2012.

BAKHTIN, Mikhail; (VOLOCHINOV, V. N.). Marxismo e filosofia da linguagem: problemas fundamentais do método sociológico na ciência da linguagem. São Paulo: Hucitec, 1995.

. Estética da criação verbal. Tradução Paulo Bezerra. 6. ed. São Paulo: Martins Fontes, 2011.

BELMIRO, Célia Abicalil. Entre os modos de ver e os modos de ler, o dizer. Educação em Revista, Belo Horizonte, v. 28, n. 4, p. 105-131, dez. 2012.

BENJAMIN, Walter. Obras escolhidas I: magia e técnica, arte e política. São Paulo: Brasiliense, 1994.

BRENMAN, Ilan; MORRICONI, Renato. Telefone sem fio. São Paulo: Companhia das Letrinhas, 2010.

CHARTIER, Roger. A ordem dos livros: leitores autores e bibliotecas na Europa entre os séculos XIV e XVIII. Brasília: Editora UNB, 1994.

(Org.). Práticas da leitura. São Paulo: Estação Liberdade, 2009.

COLOMER, Teresa. Andar entre livros: a leitura literária na escola. São Paulo: Global, 2007.

CORSINO, Patricia. Infância e linguagem em Walter Benjamin: reflexões para a educação. In: JOBIM E SOUZA, Solange; KRAMER, Sonia (Org.). Política, cidade, educação: itinerários de Walter Benjamin. Rio de Janeiro: Contraponto, 2009. p. 219-241.

- Literatura na educação infantil: possibilidades e ampliações. In: PAIVA, Aparecida (Org.). Literatura: ensino fundamental. Brasília: Ministério da Educação, Secretaria de Educação Básica, 2010. p. 183-204. (Coleção Explorando o Ensino).

FRANCHI, Carlos. Linguagem atividade constitutiva - teoria e poesia. São Paulo: Parábola Editorial, 2011.

FREITAS, Maria Teresa. A perspectiva sócio-histórica: uma visão humana da 
construção do conhecimento. In: FREITAS, Maria Teresa; JOBIM E SOUZA, Solange; KRAMER, Sonia (Org.). Ciências humanas e pesquisa: leituras de Mikhail Bakhtin. São Paulo: Cortez, 2003. p. 26-38.

GERALDI, João Wanderlei. Portos de passagem. 4. ed. São Paulo: Martins Fontes, 1997.

. A linguagem nos processos sociais de constituição da subjetividade. In: VAL, M. da G. C. Reflexões sobre práticas escolares de produção de texto: o sujeito-autor. Belo Horizonte: Autêntica, 2003.

HOUAISS, A. Dicionário Houaiss da língua portuguesa. Rio de Janeiro: Objetiva, 2009.

KLEIMAN, Angela. Leitura: ensino e pesquisa. Campinas: Pontes, 1996.

LARROSA, Jorge. Notas sobre a experiência e o saber de experiência. Revista Brasileira de Educação, Campinas, n. 19, p. 20-28, jan.-abr. 2002.

MACHADO, Ana Maria. Boladas e amigos. Rio de Janeiro: Salamandra, 1995. MANGUEL, Alberto. Uma história de leitura. São Paulo: Companhia das Letras, 1997.

PEREIRA, Maria Antonieta. Jogos de linguagem, redes de sentido: leituras literárias. In: PAIVA, Aparecida; MARTINS, Aracy; PAULINO, Graça; VERSIANI, Zélia. Literatura - saberes em movimento. Belo Horizonte: Autêntica, 2007.

PERROTTI, Edmir. Lugares da leitura: a escola como espaço de leitura. Boletim Salto para o Futuro - Espaços de Leitura. Rio de Janeiro, TVE- Brasil, p. 8-18, 2004.

REYES, Yolanda. Ler e brincar, tecer e cantar: literatura, escrita e educação. São Paulo: Editora Pulo do Gato, 2012.

SILVA, Marcia Cabral da; MARTINS, Milena Ribeiro. Experiências de leitura no contexto escolar. In: PAIVA, Aparecida (Org.). Literatura: ensino fundamental. Brasília: Ministério da Educação, Secretaria de Educação Básica, 2010. p. 2340. (Coleção Explorando o Ensino).

VYGOTSKY, L. S. Pensamento e linguagem. São Paulo: Martins Fontes, 1993. YUNES, Eliana. Pelo avesso: a leitura e o leitor. Revista de Letras, Curitiba, $n$. 44, p. 185-196, 1995.

. Leitura como experiência. In: YUNES, Eliana; OSWALD, Maria Luiza (Org.). A experiência da leitura. São Paulo: Loyola, 2003. p. 7-15. 
Sobre a autora:

Rafaela Vilela é doutoranda em Educação pela Universidade Federal do Rio de Janeiro e professora do Instituto Superior de Educação Pró-saber.

rafalouise@gmail.com

Recebido em: outubro de 2015

Aprovado em: novembro de 2015 